\title{
SEGREGATION OF METALS AND NON- METALS USING PLC AND SCADA
}

\author{
Niha Shariff \\ Industrial Automation and Robotics \\ Department of Mechanical Engineering \\ Malnad College of Engineering, Hassan, Karnataka, \\ India
}

\begin{abstract}
In this project, it proposes an automatic segregation of metals and nonmetals which is a cheap, easy to use solution for a segregation systems. ProximityInductive and Proximity-Capacitive sensors are used for detecting the metal or nonmetal type of object and each object which is moving on a conveyor belt are detected by inductive sensor, with the help of hydraulic cylinders. The controlling is done by PLC and metal objects are separated from the non-metallic objects. SCADA interfaced with PLC has been used for monitoring entire process.
\end{abstract}

Keywords-PLC, automatic conveyor belt, proximity sensors, hydraulic cylinders, SCADA.

\section{INTRODUCTION}

In India about 60 million tons of waste is being generated every year. Ten million tons of garbage is generated in metropolitan cities. The landfills of most of these cities are overflowing with no space for fresh garbage waste. The philosophy of "waste management hierarchy" has been adopted by most nations as the step for developing municipal solid waste (MSW) management strategies. According to sanitation survey called ministry of urban development under Swachh Bharath mission, it was found that about $50 \%$ of people in India face the problem of improper waste collection and management. According to centre of science and environment innovative disposal and recycling methods must be introduced instead of landfill sites.

In general, the developed countries generate much higher quantities of waste per year compared to the developing countries of the region. However, in certain circumstances the management of even small quantities of waste is a significant challenge. For example, in the small islands of the South Pacific sub-region, small populations and modest economic activity have ensured that relatively low quantities of waste are generated. However, many of these countries, particularly small countries such as Kiribati, Tuvalu and the Marshall Islands, face considerable waste management challenges due to their small land areas and resultant lack of disposal option.
Throughout the region, the principal sources of solid waste are residential households, agricultural, commercial, construction, industrial and institutional sectors.

\section{METHODOLOGY}

In order to control the entire process automatically PLC is used. A conveyor arrangement is attached with proximity and photoelectric sensors is interfaced with PLC. A capacitive type photoelectric sensor is used for deducting the waste, inductive type proximity sensor is used for deducting metals in it.

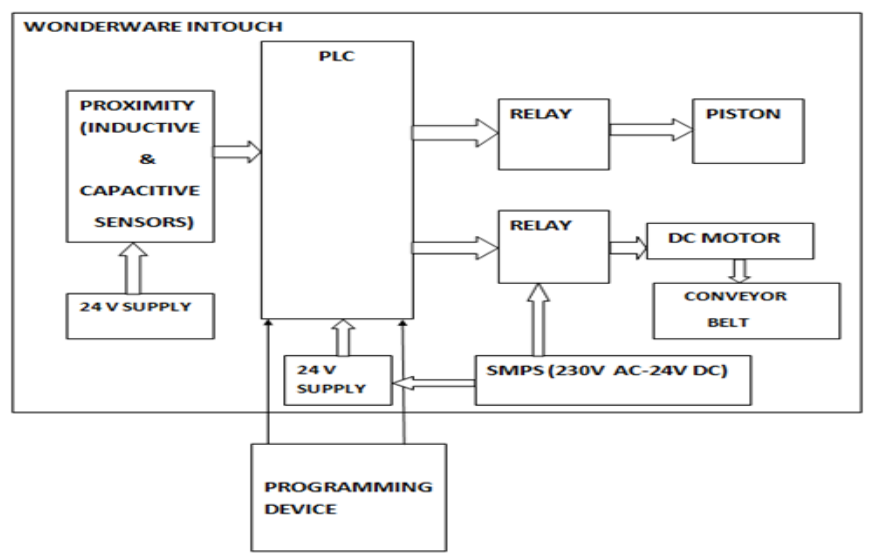

Fig.1. Block diagram of PLC and SCADA based segregation system.

The conveyor has two step arrangements with a sensors and piston. Whenever capacitive type sensor goes on it will turn on the motor. Where inductive type sensor will activate the double acting cylinder for metal separation. Direction control valve of electric type is used to control the direction of air pressure. Thus the separated metals can be effectively used for recycling process. This entire project will be monitored using SCADA, which got interfaced with PLC. 
International Journal of Engineering Applied Sciences and Technology, 2019

Vol. 4, Issue 2, ISSN No. 2455-2143, Pages 197-200

Published Online June 2019 in IJEAST (http://www.ijeast.com)

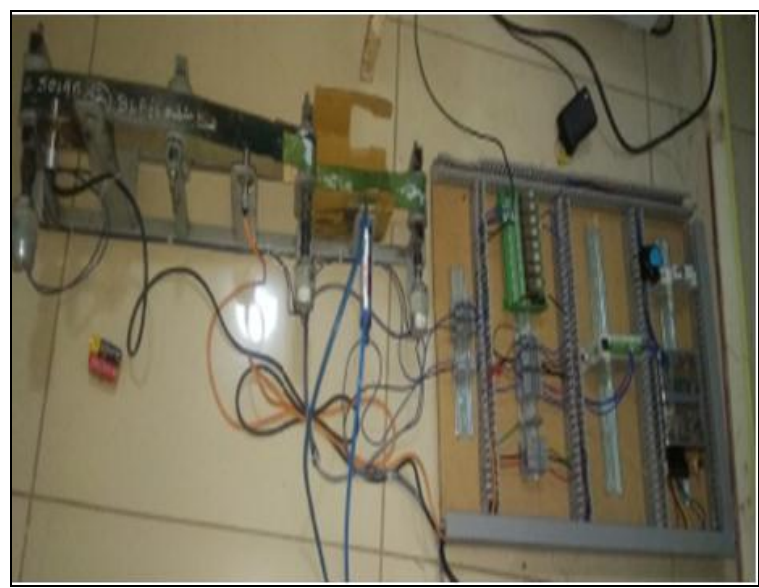

Fig.2: Switch mode power supply

Hardware Components:

\section{Delta PLC:}

PLCs are designed for multiple analogue and digital inputs and output arrangements, extended temperature ranges, immunity to electrical noise and resistance to vibration and impact. Programs to control machine operation are typically stored in battery-backed-up or non-volatile memory. The PLC which is used in this system is Delta.

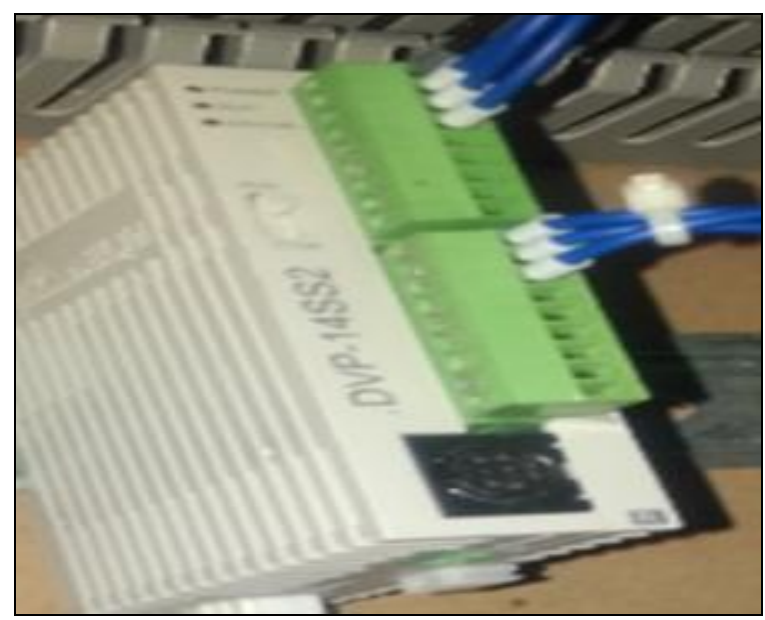

Fig.3: Delta PLC

2. Switched Mode Power Supply:

Switch mode power supplies (SMPSs) are used in a range of applications as an efficient and effective source of power. Basically, it is a device in which energy conversion and regulation is provided by power semiconductors that are continuously switching "on" and "off" with high frequency. SMPS offers advantages in terms of size, weight, cost, efficiency and overall performance.

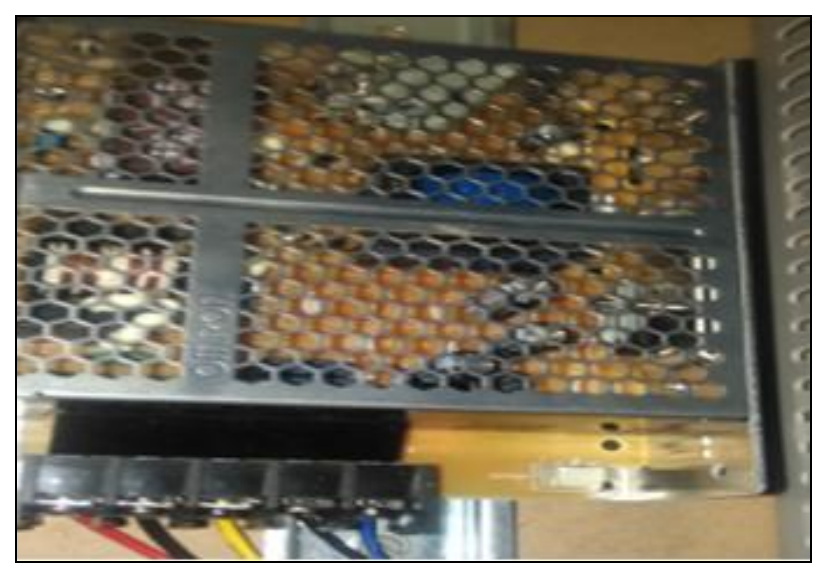

Fig.4: Switch mode power supply

3. Relay cards:

Relay cards is used as switching as well as protecting device for the whole circuit.

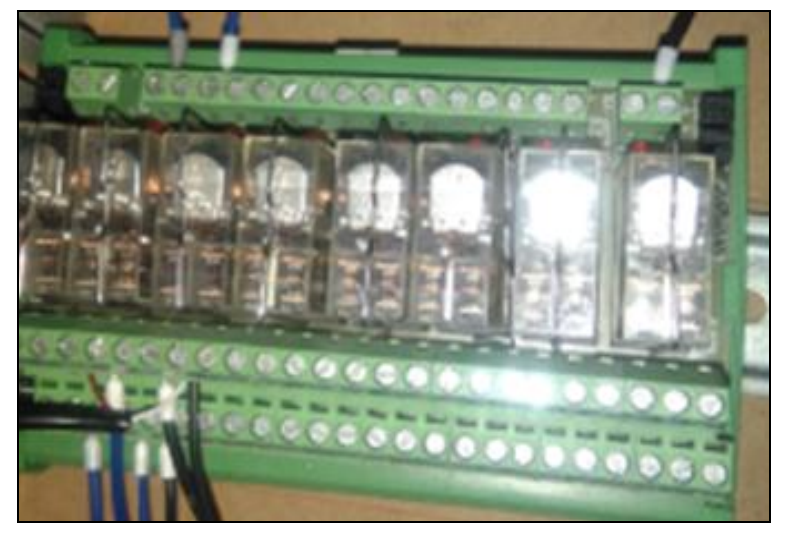

Fig.5: Relay cards

4. Double acting cylinder:

Double Acting Cylinders are equipped with two working ports- one on the piston side and the other on the rod side.

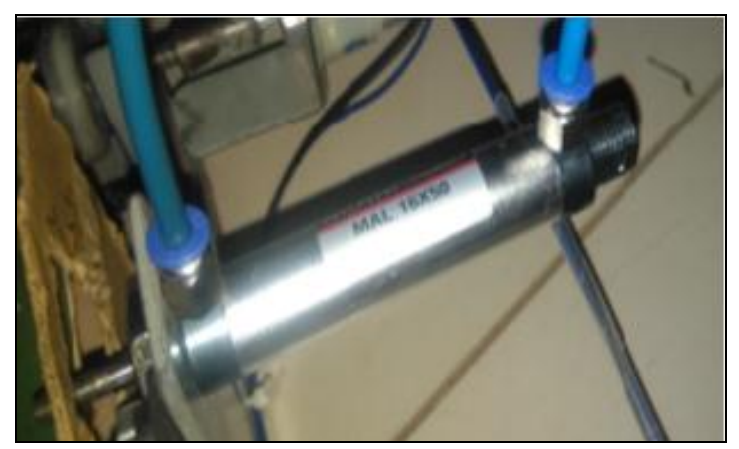

Fig.6: Double Acting Cylinder 


\section{Push Button:}

A push button is a simply switch mechanism for controlling some aspect of a machine or a process.

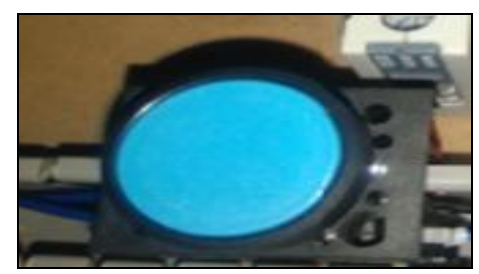

Fig.7: Push Button

\section{SOFTWARE IMPLEMENTATION}

There are three software are used for implementing PLC and SCADA.
1. WPL Soft
2. KEPSERVEREX
3. Wonderware InTOUCH

1. WPL Soft: WPL Software is the program editing software made for the Delta DVP-PLC series used under WINDOWS.PLC is a digital computer used for automation of typically industrial electromechanical processes such as assembly line control, amusement light or light fixtures.

2. KEPSERVEREX: It provides a single source of industrial automation data to all the applications and provide security policies based on user role.

3. Wonderware InTouch:

Intouch provides three windows for process creation

1. Application Manager

2. Window maker

3. Window viewer

\section{APPLICATION MANAGER:}

\begin{tabular}{|c|c|c|c|c|c|c|}
\hline \multicolumn{7}{|l|}{ 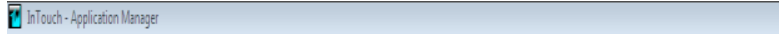 } \\
\hline \multicolumn{7}{|l|}{ fle Ver Jools Hepp } \\
\hline \multicolumn{7}{|c|}{ 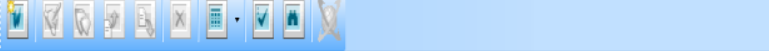 } \\
\hline Name & Path & Resoldton & Vesil... & Applaction.... & Applic... & Dott Modfed Description \\
\hline Hiller hilouch appliction & 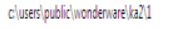 & $0 \times 0$ & 0 & Stand Alone & 0 & 1219/21818 ... MevinTouch application \\
\hline (th New hTouch appliction:2] & 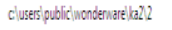 & $0 \times 0$ & 0 & Stand Alone & 0 & 121992018 ... New histouch application \\
\hline B New hTouch appliction3] & 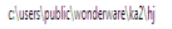 & 1024768 & 101 & StandAlone & 11 & $317701919 \mathrm{~g} . \mathrm{N}$. \\
\hline (Bt New hTouch appliction(t) & 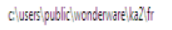 & $104 \times 768$ & 101 & Stand Alone & 8 & 3210019 z. New hiouch appliction \\
\hline 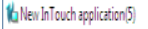 & 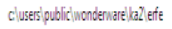 & $1024 \times 68$ & 10.1 & Stand Alone & 4 & 321:019 4..... New hToush application \\
\hline B WNer hTouch applictionb] & 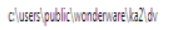 & 1366768 & 101 & SandAlone & 23 & $427 / 019 \mathrm{~g}$. New hTouch appliction \\
\hline Bd New hTouch appliction?] & 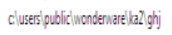 & 1366768 & 10.1 & Stend Alone & 12 & 515/2019 6... New hTouch application \\
\hline
\end{tabular}

Fig.8: Application Manager Window
The above figure shows application manager window of wonder ware intouch, used for creating the project document name and path to get saved.

\section{Window maker:}

Used for designing the entire process through animations provided in it. It has several pictorial animations in Wizards sector and all industrial based animations in symbol factory.

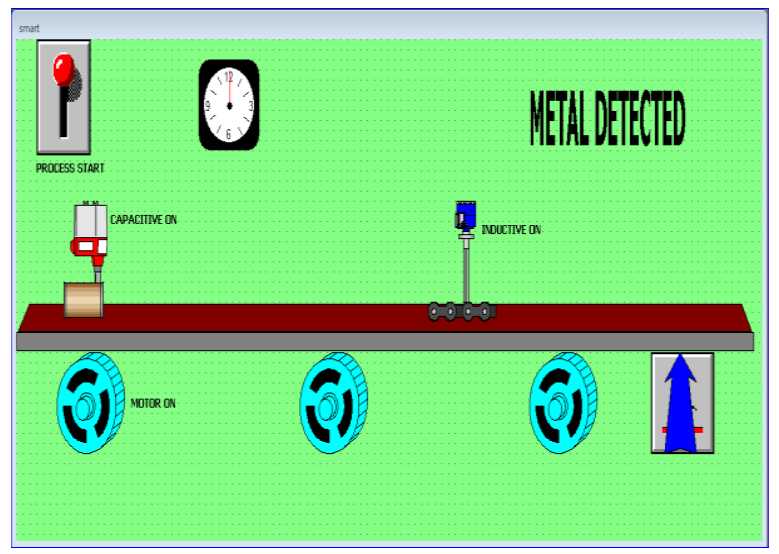

Fig.9:Animation for the smart segregation

The above figure shows the animations done for the smart segregation process. According to these animations the object moves based on the motion of waste dumped in smart dustbin. Once when the inductive sensor is ON the object will get converted into metal. When the piston is activated the process stops after one or two seconds, again if the waste dumped in the sense the push has to be triggered again.

\section{Window viewer:}

The runtime of window maker is window viewer, the animations which was created in window maker can be monitored in this window, multiple windows can be monitored by selected the file one by one.

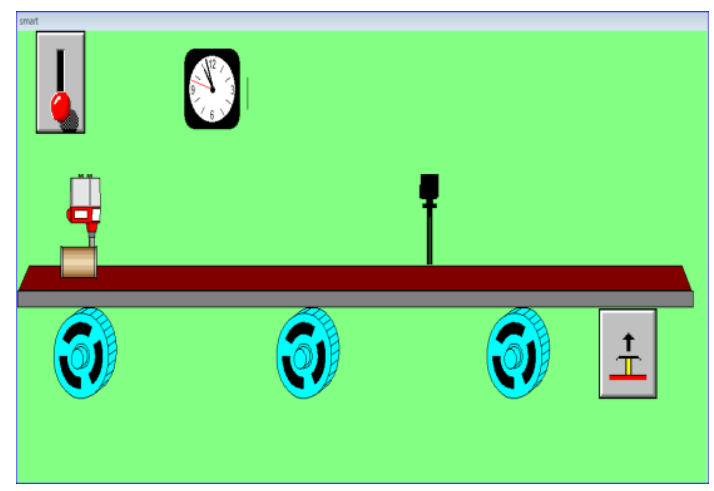

Fig.10: Device activated based on Real time moment

All the devices which got connected will get activated based on the real time moment. 


\section{International Journal of Engineering Applied Sciences and Technology, 2019 \\ Vol. 4, Issue 2, ISSN No. 2455-2143, Pages 197-200 \\ Published Online June 2019 in IJEAST (http://www.ijeast.com)}

\section{EXPERIMENT AND RESULT}

In order to control the entire process automatically PLC is used. A conveyor arrangement is attached with proximity and photoelectric sensors are interfaced with PLC. A capacitive type photoelectric sensor is used for detecting the presence or absence of object, inductive type proximity sensor is used for detecting metals. The conveyor has two step arrangements with a sensors and piston. Whenever capacitive type sensor goes on it will turn on the motor. Where the double acting cylinder activates metal objects get separated. Direction control valve of electric type is used to control the direction of air pressure. Thus the separated metals can be effectively used for recycling process. This entire project will be monitored using SCADA, which got interfaced with PLC.

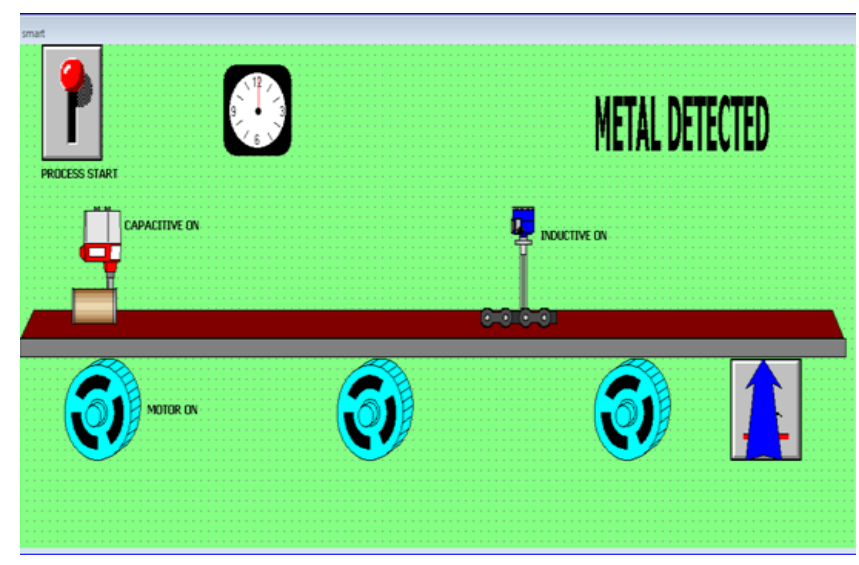

Fig.11: SCADA screen of the working model where metal detection is indicated.

\section{CONCLUSION}

This paper is regarding an automatic segregating system using the PLC and SCADA. This system segregates the metal and non-metal objects by using Proximity-Inductive sensors which is arranged on a conveyor belt. All the metal objects are separated with the help of hydraulic cylinder piston arrangement. The entire process is programmed by using PLC and monitored using SCADA. In Future, the work can be implemented by making use of a robotic arm to pick and place certain materials which can be re-used. Also, limit sensors can be placed at the top of each of the collecting bins to unload them when they are full.

\section{REFERENCE}

[1] Joice Johny et.al.,(2013), “Automatic Plastic Separating Technology For Solid Waste Disposal", International Journal of Civil, Structural, Environmental and Infrastructure Engineering Research and Development (IJCSEIERD)ISSN 2249-6866Vol. 3, Issue 2, Jun 2013, 99-108 (C) TJPRC Pvt. Ltd.

[2] Prof. Mr. P. Balramdu et.al.,(2014), “ Remote Monitoring and Sorting System for Waste Material Management
Using RFID”,International Journal of Advanced Research in Computer Engineering \& Technology (IJARCET) Volume 3 Issue 10, October 2014.

[3] Y V Aruna et.al.,(2015), “Automatic convey or System with In-Process Sorting Mechanism using PLC and HMI System", Int. Journal of Engineering Research and Applications ISSN: 2248-9622, Vol. 5, Issue 11, (Part - 3) November 2015, pp.37-42.

[4] S.M .Dudhal et.al.,(2014), “waste segregation using programmable logic controller", ijtre, Volume 1, Issue 8, April 2014.

[5] Nidhi Mishra et.al.,(2014) , "Plc Based Scrap Management System", Rani B. Phulpagar et al Int. Journal of Engineering Research and Applications ISSN : 22489622, Vol. 4, Issue 3( Version 1), March 2014, pp.26-2.

[6] M.K.Pushpa et al.,(2015), "Microcontroller Based Automatic Waste Segregator", International Journal of Innovative Research in Electrical, Electronics, Instrumentation and Control Engineering, Vol. 3, Issue 5, May 2015.

[7] Subhasini Dwivedi et al.,(2016), “A Review on PLC based Automatic Waste Segregator”, International Journal of Advanced Research in Computer Engineering and Technology, Volume 5, Issue 2, February 2016.

[8] Athira J et al.,(2016), “An Economic Automatic Waste Segregator using Arduino", International Journal of Research in Advent Technology, Vol.4, No.7, July 2016.

[9] Aishwarya Bhojkar et al.,(2017), "Waste Management Using PLC", International Journal of Electrical, Electronics and Computer Systems, ISSN 2347-2820, Volume -5, Issue-2, November 2017.

[10] M. Arun Kumar et al.,(2018), "Programmable Logic Controller based Metal Segregation in Steel Industry", International Journal of Advanced Research in Electrical, Electronics and Instrumentation Engineering, Vol. 7, Issue 2, February 2018.

[11] Rahul Deshmukh et al (2018), "Material Segregation \& Waste Management using PLC", International Journal of Engineering Technology Science and Research, Volume 5, Issue 3 March 2018.

[12] K.G.Suhirdham et al (2018), "Automatic Material Segregation using PLC", International Journal of Engineering Technology, Vol7, Issue 2, April 2018. 